\title{
Effect of T0901317 on promoting the differentiation of human bone marrow mesenchymal stem cells into dopamine neurons on Parkinson's disease
}

\section{Miaomiao Li}

Chongqing Medical University

Junqing Yang

Chongqing Medical University

Oumei Cheng

Chongqing Medical University

\section{Zhe Peng}

Chongqing Medical University

Yin Luo

Chongqing Medical University

\section{Dongzhi Ran}

Chongqing Medical University

\section{Yang Yang}

Chongqing Medical University

\section{Pu Xiang}

Chongqing Medical University

Haifeng Huang

Chongqing Medical University

Xiaodan Tan

Chongqing Medical University

Hong Wang ( $\nabla 101832 @ c q m u . e d u . c n)$

Chongqing Medical University

\section{Research}

Keywords: Human bone marrow mesenchymal stem cells; Parkinson's disease; Liver X receptor agonist; T0901317; Differentiation; Cell transplantation.

Posted Date: May 27th, 2020

DOl: https://doi.org/10.21203/rs.3.rs-15406/v3 
License: (c) (i) This work is licensed under a Creative Commons Attribution 4.0 International License. Read Full License 


\section{Abstract}

Background: Stem cells from different sources could differentiate into dopamine-producing cells and ameliorate behavioral deficits in Parkinson's disease (PD) models. Especially, human bone marrow mesenchymal stem cells (hBMSCs) have many advantages without ethical dispute. Liver $\mathrm{X}$ receptors (LXRs) are involved in the maintenance of the normal function of the central nervous system myelin. The previous work of our team have reported the induction of cocktail-induced da phenotypes from adult rat BMSCs by using sonic hedgehog (SHH), fibroblast growth factor 8 (FGF8), basic fibroblast growth factor (bFGF) and T0901317 (agonist of LXRs) with $87.42 \%$ of efficiency in 6 days of period of induction. But it did not verify whether the induced cells had the corresponding neural function.

Methods: The present study was to investigate the effect of T0901317 on the differentiation of hBMSCs into dopaminergic (DA) neurons. In vitro, the cells were divided into control group, GF group and LXR+GF group. Neuronal markers (Tuj1, Neun and Nestin) and DA neuron markers (tyrosine hydroxylase, TH) were detected to explore the optimal concentration, optimal addition time and optimal induction time of T0901317 to promote hBMSCs differentiation. Determine induced cells' DA neuron properties by detecting dopamine release. To clarify its underlying mechanisms, the expressions of LXRa, LXRb and ABCA1 were detected. In vivo, male Sprague Dawley (SD) rats were divided into control group, 6-OHDA group (model group) and 6-OHDA+Cells group (cell transplantation group) to observe whether cell transplantation had a therapeutic effect on PD.

Results: T0901317 significantly enhanced the differentiation of hBMSCs into DA neurons. Compared to control group and GF group, only the LXR+GF group released dopamine by the result of enzyme linked immunosorbent assay (ELISA). Compared with the control group and GF group, the optimal time for differentiation of hBMSCs treated by $0.5 \mathrm{mM}$ T0901317 combined with GF was six days in LXR+GF group. And the maximum induction efficiency of differentiation of hBMSCs into DA neurons was $91.67 \%$ in LXR+GF group. After the long-term use of T0901317, LXRa and LXR $\beta$ decreased significantly, and ABCA1mRNA increased significantly in LXR+GF group. After induced-cells were transplanted into PD rats, Compared with 6-OHDA group, the expression of TH in the striatum increased significantly, and the behavior of PD rats induced by apomorphine was significantly improved in the 6-OHDA+Cells group.

Conclusions: T0901317 promoted differentiation of hBMSCs into DA neurons may be related to activation of LXR-ABCA1 signaling pathway. These data suggested that T0901317 may serve as a potential therapeutic methods for PD.

\section{Introduction}

Parkinson's disease (PD) is a complex, age-related neurodegenerative disease with early prominent death and loss of dopaminergic (DA) neurons in substantia nigra (SN) ${ }^{1,2}$. The main clinical manifestations of PD are static tremor, increased muscle tone and unstable posture. PD is also closely related to various non-motor symptoms, such as cognitive dysfunction, mood and psychotic disorder ${ }^{3}$. A considerable 
number of patients have cognitive impairment in late stage of PD. Non-motor symptoms might be present up to 20 years before manifestation of the characteristic motor symptoms ${ }^{4}$.

PD is associated with cholinergic and monoaminergic neurons, and oligodendrocytes play an important role in $\mathrm{PD}^{5}$. Traumatic brain injury, post-traumatic stress disorder ${ }^{6}$, history of melanoma and exposure to pesticides are increased risk of $\mathrm{PD}^{7}$. In the degenerative diseases of the nervous system, the incidence of PD in the 65 -year-old population is more than $1 \%$, second only to Alzheimer's disease, and it escalates burden on economic terms and quality of life to these patients' families and society.

The main managements of PD are drug therapy, surgical treatment and stem cell replacement therapy. Drug therapy mainly improves the symptoms of patients by increasing the concentration of dopamine in the brain. But it is important to consider the side-effects and tolerance levels of the patient ${ }^{8}$. Surgical treatments include thalamicectomy and deep brain stimulation (DBS). Thalamotomy is an intrusive technique. Although it can relieve the tremor of PD patients well, it seems to alter the physiological regulation of PD patients and cause motor dysfunction ${ }^{9}$. When PD patients' symptoms do not respond to medication adjustments, DBS treatment needs to be started. It can significantly control dyskinesia induced by levodopa in the treatment of PD. However, for this invasive treatment, PD patients must experience surgery again and again. It increases the risk of infection of them ${ }^{10}$. Currently available drugs or surgery are merely symptomatic treatments and do not slow down or prevent the progress of the disease. Some data suggested that supplementing brain-lost DA neurons by cell transplantation may be the most promising therapy for PD ${ }^{11}$. A more immediate and reachable goal of cell transplantation may be neuronal protection ${ }^{12}$. Currently, embryonic stem cells (ESCs), neural stem cells (NSCs), induced pluripotent stem cells (iPSCs) and bone marrow mesenchymal stem cells (BMSCs) are available for stem cell replacement therapy ${ }^{13}$. The use of ESCs and NSCs existed ethical problems inherent. So much hope is transferred to iPSCs which induced human fibroblasts into a source of patient-specific and diseasespecific neurons, especially as, in theory, this approach would avoid many of the ethical issues associated with using ESCs ${ }^{14,15}$. Cell replacement therapy is derived from the patient's own cells without immune rejection. In autologous transplantation, it is necessary to establish iPSCs from each patient, and current technical operations take much time and high cost, so it is difficult to spread to general treatment. In addition, the iPSCs own the patient's own genetic factors, the sensitivity of the disease may be high. It also has high risk of introducing cancer cells ${ }^{16}$. Specifically, iPSCs often obtained chromosomal abnormalities, with gains or losses of whole chromosomes ${ }^{17}$. Different from these stem cells, BMSCs come from patients themselves without ethics dispute. Especially, BMSCs have multi-directional differentiation potential ${ }^{18}$, low risk of tumorigenesis ${ }^{19}$ and rich in source. Many studies in vitro and preclinical strongly proved the therapeutic potential of BMSCs when be applied as a treatment for different pathological conditions ${ }^{20,21}$.

There have been different methods involved in the differentiation of BMSCs into DA neurons, including cell growth factors ${ }^{22,23}$, chemical inducer ${ }^{24}$ and lentiviral transduction ${ }^{25}$. Currently, in vitro induction of stem cells using growth factors with sonic hedgehog ( $\mathrm{SHH}$ ) and fibroblast growth factors (FGFs), 
succeeded in inducing adult human BMSCs into DA neurons with $67 \%$ of efficiency in 12 days ${ }^{26,27}$. This is the maximum induction efficiency and the shortest induction time.

Liver $X$ receptors (LXRs) include LXRa and LXRß. It are the member of the nuclear receptor supergene family of ligand-activated transcription factors and is a major regulator of lipid metabolism ${ }^{28}$. It play a key role in the regulation of cholesterol and fatty acid homeostasis ${ }^{29}$. LXRs is also essential for central nervous system (CNS) ${ }^{30,31}$. The loss of LXRß in mice affected the formation of progenitor cells and granule cell differentiation, and then leading to hypoplasia of the dentate gyrus ${ }^{32}$. It has been found that LXRs played crucial roles in regulation of genes related to CSF production and structural integrity of choroid plexus ${ }^{33}$. LXRa and LXRß are involved in the processes of myelination and remyelination ${ }^{34}$. Activation of LXRa and LXR $\beta$ can promote the regeneration and survival of motor neurons ${ }^{35}$. Meanwhile, LXR agonists activate LXR target genes, plays therapeutic role in different neurodegeneration animal models ${ }^{36-38}$. Therefore, we speculate whether LXR agonists have a therapeutic effect on PD and whether they can promote the formation of DA neurons.

Our previous work have found the induction of cocktail-induced da phenotypes in adult rat BMSCs by using SHH, fibroblast growth factor 8 (FGF8), basic fibroblast growth factor (bFGF) and T0901317 with $87.42 \%$ of efficiency in 6 days of period of induction ${ }^{39}$. LXR agonists significantly shortened induction time and improved induction efficiency compared to methods which had been reported. But these previous work of our team did not investigate whether induced-cells released dopamine. We did not sure if the induced cells have a therapeutic effect on Parkinson's disease.

In this study we investigated the effect of T0901317 on the differentiation of hBMSCs into DA neurons. We also explored whether induced-cells had dopamine neuronal function and the possible mechanism. Finally, we transplanted the induced-cells into PD rats to observe the therapeutic effect.

\section{Materials And Methods}

\section{Materials}

6-hydroxydopamine (6-OHDA) was purchased from Selleck. Human bone marrow mesenchymal stem cells (hBMSCs) was purchased from Cyagen Biosciences. LXR agonist-T0901317 (N-(2, 2,2-trifluoroethyl)-N-[4-(2,2,2-tri-fluoro1-hydroxy-1-trifluoromethyl-ethyl)-phenyl]-benzenesulfonamide) was purchased from Sigma-Aldrich. Apomorphine hydrochloride was purchased from Pharmaceutical Factory of Qinghai, China. Goat serum was purchased from Beijing Dingguo Changsheng Biotechnology, China.

\section{Animals}

Sprague-Dawley (SD) rats were accommodated in the barrier housing facility, in keeping with the national standard of "Laboratory Animal-Requirements of Environment and Housing Facilities." The care of the laboratory animal and the animal experimental operation conform to the "Chongqing Administration Rule 
of Laboratory Animal." The experimental procedures were approved by the animal laboratory administrative center and the institutional ethics committee of Chongqing Medical University (License number: SYXK YU 2018-0003).

\section{Parkinson's disease rats}

All male SD rats were weighted $220 \mathrm{~g}-250 \mathrm{~g}$. To establish the rat model of PD, All SD rats received intraperitonal injection of apomorphine $(0.5 \mathrm{mg} / \mathrm{kg})$. Rats were selected without rotation behavior to receive a 6-OHDA lesion of the medial forebrain bundle on the right side (MFB, AP: 1.8mm, ML: $2.0 \mathrm{~mm}$, DV: $8.0 / 7.8 \mathrm{~mm}$ ). 30 male rats received a 6-OHDA lesion of the MFB on the right side and 10 rats were as control group only injected with solvent which was used to dissolve 6-OHDA ${ }^{40,41}$. Briefly, rats were anesthetized with chloral hydrate ( $4 \%$ chloral hydrate and $96 \%$ saline solution, $1 \mathrm{ml} / 100 \mathrm{~g}$ ) by intraperitoneal injection. The MFB was targeted with an injection of $4 \mu \mathrm{l} 0.02 \% \mathrm{~L}$-ascorbic acid saline solution containing a total amount of $16 \mu \mathrm{g}$ of $6-\mathrm{OHDA}$. The lesion to stereotaxic coordinates were adjusted to the age and weight of the animals with the help of brain stereotaxic instrument $(R W D$, Shenzhen, China). After two weeks to one month, to determine whether the models were successful, we used apomorphine to induced rotation and behaviour was recorded over a period of $30 \mathrm{~min}$. Judging that the model is successful is that the number of rotations to the healthy side is more than 7 rotations per minute.

\section{Differentiation of hBMSCs}

Human BMSCs were divided into 3 groups and plated onto 24 well plates where each plate contained $2.0 \times 10^{4}$ cells and cells were cultured at $37^{\circ} \mathrm{C}$ with $5 \% \mathrm{CO} 2$.

Control group: hBMSCs were cultured in Dulbecco's Modified Eagle Medium/Nutrient Mixture F-12 (DMEM/F-12, Gibco) supplemented with 10\% heat-inactivated fetal bovine serum (FBS, BI) with 24 hours. After that, the medium was replaced with neurobasal medium (Invitrogen/Gibco, USA) and 0.5\% B27 supplement (Invitrogen/Gibco, USA).

Growth factors treated group (GF): hBMSCs were cultured in DMEM/F-12 containing 10\% FBS with 24 hours. After that, the medium was replaced with neurobasal medium and $0.5 \%$ B27 supplement. The cells were induced only once with a cocktail of $250 \mathrm{ng} / \mathrm{ml}$ Recombinant Human SHH (PeproTech, Rocky Hill, NJ, USA), 100 ng/ml Recombinant Human FGF8 (PeproTech, Rocky Hill, NJ, USA), and $50 \mathrm{ng} / \mathrm{ml}$ Recombinant Human basic-FGF (bFGF; PeproTech, Rocky Hill, NJ, USA). The medium was not replaced in 12 days.

T0901317 and growth factors treated group (LXR+GF): On the basis induction of GF, effects of T0901317 on the differentiation of hBMSCs into DA neurons in the time-dependent and concentrationdependent manner were investigated. According to the results of (a) (b) and (c), the cells were induced only once with the cocktail and the medium was not replaced during the induction period. 
Explore the best concentration of T0901317 added: Different concentrations of T0901317 (0.125, 0.25, $0.5,1$ and $2 \mu \mathrm{M})$ were added with GF (250ng/ml SHH, 100ng/ml FGF8, 50ng/ml bFGF).

Explore the best time to add T0901317 during growth factor induction period: On the basis of GF, T0901317 were added on the first day, the third day, the sixth day, and the ninth day, respectively, to induce differentiation for 12 days.

Explore the induction time of the T0901317 in combination with GF: According to the result of (a) (b), 0.5 $\mu \mathrm{M}$ T0901317 was added to the culture medium, and the cell morphology was observed every 3 days.

\section{Cell Counting kit-8 assay}

A Cell Counting Kit-8 (CCK-8; Dojindo, Japan) assay was used to test the growth rate by following the manufacturer's instructions. 3000 cells/well of hBMSCs were cultured into a 96-well plate in every group. At 3-day intervals, the growth rates of cells in each group were measured by application of CCK-8 kit and optical density (OD) was determined at $450 \mathrm{~nm}$ using a microplate reader (Thermo Scientific, USA).

\section{Immunofluorescence}

In brief, cells of each group were fixed in $4 \%$ paraformaldehyde and permeabilized with $0.3 \%$ Triton-X100 and blocked in phosphate buffer solution (PBS) containing 5\% normal goat serum (Beijing Dingguo Changsheng Biotechnology, China). Cells were incubated with monoclonal antibodies overnight with $4^{\circ} \mathrm{C}$. Antibodies' dilutions were as follows: $\beta$ III tubulin, 1:200 (Tuj1; Abcam, Cambridge, UK); Tyrosine hydroxylase, 1:200 (TH, Abcam, Cambridge, UK); Nestin, 1:200 (Abcam, Cambridge, UK); Neun, 1:200 (Abcam, Cambridge, UK); LXR a receptor, 1:200 (Abcam, Cambridge, UK); LXR $\beta$ receptor, 1:200 (Gene Tex, USA). After extensive washing for 3 times in PBS, suitable secondary antibodies anti-mouse IgG-Alexa Fluor 488, anti-rabbit IgG-Alexa Fluor 488, anti-mouse IgG-Cy3, anti-rabbit IgG-Alexa Fluor 594 were diluted at 1:200 in PBS, and then suitable secondary antibodies were added and incubated in darkness for $1 \mathrm{~h}$ at room temperature. Then nuclear stain 4, 6-diamidino-2-phenylindole (DAPI; Beyotime Biotechnology, Shanghai, China) was used for nuclear staining.

\section{Enzyme-Linked Immunosorbent Assay (ELISA)}

To investigate whether cells in each group release dopamine. Culture supernatant and cells of control group, GF group and LXR+GF group were collected. Cells were added with PBS, then grinded on ice. The mixture was centrifuged at $3000 \mathrm{~g}$ for $20 \mathrm{~min}$ at $4^{\circ} \mathrm{C}$ and collected the supernatants. Dopamine was detected by ELISA kits $(n=6)$ (Mei biao, Jiangsu, China). The samples and standards were tested according to the instructions.

\section{Western Blotting Test}

Cells were plated on six-well plate for 24 hours with $10 \%$ FBS, then grown in induction medium for six days to be used for preparation of whole cell extract. After removing the media, cells were washed three 
times with PBS. Then cells in each well were added $150 \mathrm{ml}$ lysis buffer containing $1 \%$ phenylmethanesulfonyl fluoride (PMSF) and cracked on ice for 30 minutes. The mixture was centrifuged at $12,000 \mathrm{~g}$ for $20 \mathrm{~min}$ at $4^{\circ} \mathrm{C}$ and collected the supernatants. The protein concentration was determined by BCA Protein Assay Kit (Beyotime, China). The protein was separated by sodium dodecyl sulphate polyacrylamide gel electrophoresis (SDS-PAGE) and transferred to PVDF membranes (Millipore, United States). The membranes were blocked with $5 \%$ bovine serum albumin (BSA) for $2 \mathrm{~h}$ at room temperature and then incubated with specific primar antibodies, TH, 1:500 (Abcam, Cambridge, UK); LXR a receptor, 1:500 (Abcam, Cambridge, UK); LXR $\beta$ receptor, 1:500 (GeneTex, United States) were included and overnight at $4{ }^{\circ} \mathrm{C}$. The membranes were rinsed three times in TBST and incubated with HRP conjugated secondary antibodies at room temperature for $1 \mathrm{~h}$. Then after washed three times in TBST, protein signals were visualized by ECL (Bio-Rad, United States).

\section{Real-Time Polymerase Chain Reaction (qPCR)}

Total RNA was isolated from the cells in control group, GF group and LXR+GF group by Trizol reagent (Vazyme, Nanjing, China) according to the manufacturer's protocol. Then mRNA was subjected to reverse transcription using HiScript Q Select RT SuperMix (Vazyme, Nanjing, China). SYBR Green II (Biomake, USA) incorporation method was used to detect the amount of mRNA. Negative controls were used as no template cDNA reactions and melting curves were used to confirm the results. The results were normalized using GAPDH concentration of each sample. The primer sequences are reported in Table 1.

Table 1. List of primers used in qPCR analysis.

GENE FORWARD Sequence (5'->3')

REVERSE Sequence $\left(5^{\prime}->3^{\prime}\right)$

ABCA1 GAGGCAATGGCACTGAGGAAGATG CAACGAGCAGCGGCTTCAGAG

GAPDH CTGGGCTACACTGAGCACC

AAGTGGTCGTTGAGGGCAATG

\section{Cell transplantation}

Four weeks after 6-OHDA infusion, PD rats were divided randomly into two groups as follows: the saline group (6-OHDA group, $n=10$ ) and cells transplantation group (6-OHDA+Cells group, $n=20)$. The differentiated DA cells were dislodged by accutase cell dissociation reagent (Invitrogen/Gibco, USA). Cell suspensions of $5 \mu \mathrm{l}(100,000$ cells/ $\mu \mathrm{l})$ were transplanted in right SN (AP: $4.6 \mathrm{~mm}, \mathrm{ML}: 2.2 \mathrm{~mm}, \mathrm{DV}: 7 \mathrm{~mm})$.

\section{Histopathological Examination}

Hematoxylin and eosin (HE) staining was performed to show pathological histological damage in the substantia nigra pars compacta (SNc) and striatum. The rats of control group, 6-OHDA group and 6OHDA+Cells group were anesthetized with sodium chloral hydrate $(4 \%, 1 \mathrm{ml} / 100 \mathrm{~g})$ and perfused with PBS, and then perfusion with $4 \%$ paraformaldehyde. After that, the brains were dehydrated in a graded series of alcohols and embedded in paraffin. A series of $5-\mu \mathrm{m}$-thick sections were cut from the brain. Finally, the sections were stained with HE reagents for histopathological examination. 


\section{Statistical analysis}

All results were expressed as the means \pm standard deviation (SD) and the statistical significance of differences was analyzed by GraphPad Prism (GraphPad Software, La Jolla, CA, USA). For the comparison of multiple groups, statistical analysis was performed using one-way analysis of variance (ANOVA) with Bonferroni's posthoc test. Probability values less than $0.05(p<0.05)$ were considered to be statistically significant.

\section{Result}

\section{Morphological features of hBMSCs}

hBMSCs were purchased in Cyagen Biosciences. Cells exhibited a long fusiform and vortex arrangement (FIGURE 1).

\section{Effect of different concentrations of T0901317 on cell survival}

CCK8 kit was used to detect the survival rate of cells in control, GF and LXR+GF groups. In addition, the concentration of T0901317 in the LXR+GF group was given to $0.125 \mathrm{mM}, 0.25 \mathrm{mM}, 0.5 \mathrm{mM}, 1 \mathrm{mM}$ and $2 \mathrm{mM}$ respectively. After three days, the survival rate of cells in each group did not show significant difference (FIGURE 2A). The survival rate significantly increased in GF group and LXR+GF group compared to control group when cells were cultured for six days, nine days and twelve days. Interestingly, there was no significant difference in cell survival rate when cells were cultured with different concentrations of T0901317 (FIGURE 2).

\section{The optimal concentration of T0901317}

Immunofluorescence was used to detect the expression of neuronal markers (Neun, Nestin and Tuj1) and dopamine neuron markers $(\mathrm{TH})$.

In this study, T0901317 was used of five concentrations of $0.125 \mathrm{mM}, 0.25 \mathrm{mM}, 0.5 \mathrm{mM}, 1 \mathrm{mM}$ and $2 \mathrm{mM}$. When GF combined with $0.5 \mathrm{mM}$ T0901317, the number of $\mathrm{TH}^{+}$positive cells reached the maximum (FIGURE 3).

\section{The best time to add T0901317 into GF}

In this study, 0.5mM T0901317 was used in combination with GF to induce hBMSCs into DA neurons. On the premise of GF addition during 12 days, T0901317 was added on the first day, third day, sixth day, and ninth day. Expression of TH (Cy3, red) and Tuj1 (Alexa Fluor 488, green) were determined by immunofluorescence. The results showed that the expression of TH was the highest when T0901317 was added on the first day (FIGURE 4).

The optimal period induced by T0901317 
Immunofluorescence was used to detect the expressions of Tuj1 and TH after three days, six days, nine days and twelve days of induction period. Cells in control group only expressed Tuj1 without TH. While cells in GF group and LXR+GF group expressed Tuj1 and TH simultaneously (FIGURE 5A). In the LXR+GF group, $\mathrm{TH}^{+}$cells reached maximum after six days of induction (FIGURE 5B). Compared with control group and GF groups, the expression of TH was significantly increased in cells of LXR+GF group (FIGURE 5D). Cells showed typical neuronal morphology with extended long cell processes and enlarged cell bodies in GF group and LXR group under the bright field (FIGURE 5C). In particular, in the LXR+GF group, the morphology of the neurons expressed by the cells was more obvious (FIGURE 5E).

\section{Nestin, Neun expression and dopamine release}

Nestin, a neuroectodermal marker, seems to be a prerequisite for acquisition of the aptness to progress towards the neural lineage ${ }^{42,43}$. The cells in the control group probed with nestin and neun antibodies were negative and just revealed nuclear staining. Both GF and LXR+GF cells stained with neun and nestin (FIGURE 6A, 6B).

A dopamine kit was used to study whether differentiated hBMSCs release dopamine. The results showed that cells in control group and GF group did not secrete dopamine. Although the GF group's cells showed positive staining of neuronal markers, dopamine levels were extremely low and could not be detected in this experiment. Only the cells in the LXR + GF group had the characteristics of dopaminergic neurons, and the content of dopamine is high (FIGURE 6C).

\section{The role of LXRs in cell differentiation and its possible mechanism}

The expressions of LXRa and LXR $\beta$ did not show significant difference among control, GF and LXR+GF groups (FIGURE 7A, B). Result of western blot showed that expressions of LXRa and LXR $\beta$ were decreased significantly in LXR+GF group compared to control and GF groups (FIGURE 7C, D).

ABCA1mRNA in LXR+GF group was significantly elevated when compared to control and GF groups (FIGURE 7E).

\section{Establishment of Parkinson's disease model}

Compared with the control group, the number of contralateral rotations per min was scored. Rats with stable lesions (>7 rpm/min) were selected as PD models. The expression of TH in the model group decreased significantly. The results suggested that the PD model was successfully established (FIGURE 8).

\section{Effect of cell transplantation on PD rats}

Four weeks after injection of 6-OHDA, the apomorphine-induced contralateral rotation test was performed. the 6-OHDA+Cells group already appeared significantly improved behavioral performance compared to the rats of the 6-OHDA group (FIGURE 9F). Compared with control group, cells in 6-OHDA 
group presented significant nuclear pyknosis, vacuolization and nuclear deep staining. After cell transplantation, the nuclear deep staining of the nucleus and the vacuolization of cells in 6-OHDA+Cells were reduced (FIGURE 9A). Results revealed that TH-positive signals were almost absent at the striatum in the 6-OHDA-lesioned rats that received no grafts. In contrast, the rats in the 6-OHDA+Cells group, THpositive signals were greatly recovered in the striatum (FIGURE 9C). TH-positive signals also significantly increased at SNc in 6-OHDA+Cells group compared to 6-OHDA group (FIGURE 9B). Western blot detection also showed the same results (FIGURE 9D, E).

\section{Discussion}

PD is a complex neurodegenerative disease which is characterized by motor dysfunctions, and it also accompany non-motor symptoms. These symptoms are tightly associated with the loss and death of DA neurons. In the current research, cell transplantation has become an important topic, and it has very important significance in clinical application. Neural stem cells, embryonic stem cells, induced pluripotent stem cells and bone marrow mesenchymal stem cells have been used to the treatment of PD. Neural stem cells and embryonic stem cells exist a serious ethical dispute. As for induced pluripotent stem cells, there is a possibility of carcinogenesis. Therefore, more and more researches have been taken on BMSCs.

Some studies have shown that BMSCs expressed genes and proteins related with the neural lineage, and have been displayed to hold neurogenic differentiation potential the proper conditions in vitro ${ }^{44-46}$. BMSCs transplantation restrained multiple parameters of spinal neuroinflammation found in diabetic mice ${ }^{47}$. BMSCs can release neurotrophic factors, including GDNF and BDNF to protect neurons ${ }^{48,49}$.

In the reported studies, many methods were adopted to drive BMSCs to differentiate into DA neurons. And induction time is generally 12 days or more ${ }^{50}$. The vital method was to induce directional differentiation of cells by using cytokines. Astrocyte-derived bFGF is required for regulation of DA differentiation of the stem cells and promotes growth and survival of midbrain DA cells ${ }^{51-54}$. SHH participates in a broad array of neurodevelopmental processes in the vertebrate embryo, including morphogenesis, cell proliferation and specification, and axon pathfinding ${ }^{55,56}$. SHH exists in the postnatal and adult CNS, such as modulation of neuronal activity, progenitor cells and astrocytes as well as in differentiated neurons $\mathrm{s}^{57-59}$. FGF8 is essential for the development of multiple brain regions, such as suprachiasmatic nuclei (SCN) and hypothalamo-pituitary ${ }^{60,61}$. The development and survive of DA neurons is associated with GF-SHH and FGF8 ${ }^{62,63}$. ABCA1 affects cognitive function, leading to amyloid-beta (AB) production and apoptosis and promote neurorestoration ${ }^{64-66}$.

In the present study, our aim was to explore the effect of T0901317 on the differentiation of hBMSCs into DA neurons. We found that the growth rate of cells in GF and LXR+GF groups was initially increased and later decreased with the extension of induction time compared to control group. But the growth rate of cells in LXR+GF group was not different with GF group. We hypothesized that T0901317 had little or no effect on cell proliferation, and T0901317 may have a special effect on cell differentiation. Some studies 
have explored the effect of GF on inducing BMSCs differentiation into DA neurons, but the result were designated DA neuronal progenitors without neuronal function ${ }^{67,68}$. Our results showed that hBMSCs treated with GF alone or T0901317 combination with GF leaded to directed neuronal differentiation. T0901317 could promote differentiation of hBMSCs into DA neurons in cooperation with GF. The maximum induction efficiency was low, and the shortest induction time was 12 days when hBMSCs treated with GF alone. While the maximum induction efficiency was $91 \%$, and the shortest induction time was 6 days when hBMSCs treated with $0.5 \mu \mathrm{M}$ T0901317 in cooperation with GF. This greatly improved the efficiency of induction. Cells in GF group and LXR+GF group expressed neun and nestin. Earlier work on hBMSCs have shown the spontaneous expression of nestin in BM-MSCs and upon DA neuron induction the expression of nestin in BMSCs has been shown to get down-regulated. In recent years, some studies have shown that BMSCs have no the spontaneous expression of nestin ${ }^{69,70}$ of lower expression. And upon DA neuron induction the expression of nestin in BM-MSCs has been shown to get down-regulated up-regulated ${ }^{71}$. Therefore, we speculate that different culture media may cause different expressions of nestin. The result revealed that only cells in LXR+GF group secreted dopamine. The result suggested that T0901317 could promote the maturation of cellular functions. All of these results together indicated that simultaneous addition of T0901317 and GF could significantly improve cell differentiation efficiency and shorten induction period of hBMSCs differentiation into DA neuron-like cells and suggested that LXR may be involved in the mechanisms of hBMSCs differentiation into DA neuronlike cells.

The lack of ABCA1 leads to transport disorders of central nervous system cholesterol, which in turn leads to defects in neuronal structure and function ${ }^{72}$. Our study found that ABCA1 mRNA significantly elevated and LXRs obviously decreased in LXR+GF group compared to GF group. Differentiation of hBMSCs into DA neurons may be related to LXR-ABCA1 pathway.

The results of the studies showed that short-term xenotransplantation has less immune rejection ${ }^{73,74}$. Moreover, BMSCs have immunosuppressive effects in vivo and vitro ${ }^{75,76}$. The damage caused by 6 OHDA could be reduced after induced-cells transplantation in PD rats. Compared with the 6-OHDA group, the DA neurons in the 6-OHDA+Cells group had a significant increase. The results indicated that T0901317 can promote the differentiation of hBMSCs into DA neurons by activating the LXRs-ABCA1 signal pathway.

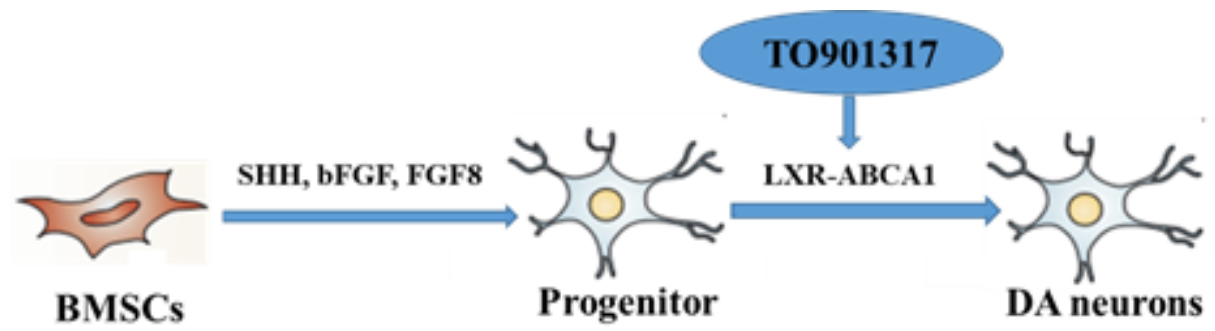




\section{Conclusions}

Collectively, based on GF to culture cells, $0.5 \mu \mathrm{M}$ T0901317 could promote the differentiation of hBMSCs into DA neurons. Induced-cells had therapeutic effect of on PD. The mechanism of T0901317 promoting the differentiation of hBMSCs into DA neurons may be related to the activation of the LXR-ABCA1 signaling pathway

\section{Abbreviations}

ABCA1: Adenosine triphosphate-binding cassette transporter A1

bFGF: Basic fibroblast growth factor

FBS: Fetal bovine serum

FGF8: Fibroblast growth factor 8

LXR: Liver X receptor

hBMSCs: Human bone marrow mesenchymal stem cells

PD: Parkinson's disease

SHH: Sonic hedgehog

HE: Histopathological Examination

TH: Tyrosine hydroxylase

OD: Optical density

\section{Declarations}

\section{Availability of data and materials}

The datasets used and/or analyzed during the current study are available from the corresponding author upon reasonable request.

\section{Funding}

Chongqing science technology commission of China provided funding for research.

\section{Acknowledgments}

This work was supported by the Chongqing science technology commission of China (NO: cstc2017shms-ZdyfX0053). 


\section{Author contributions}

Junqing Yang and Hong Wang made substantial contribution to conception, design, and performance of the study. Miaomiao Li, Junqing Yang, Oumei Cheng, Zhe Peng, Yin Luo, Dongzhi Ran, Yang Yang, Pu Xiang, Haifeng Huang, Xiaodan Tan took part in all the experiments and carried out the data analysis. Miaomiao li wrote the final manuscript and all authors approved the final manuscript.

\section{Conflicts of Interest}

The authors declare that they have no competitive interests.

\section{Ethics declarations}

\section{Ethics approval and consent to participate}

All animal experiments were approved by the Institutional Animal Care and Use Committee of Chongqing Medical University and in accordance with the Regulations for the Administration of Affairs Concerning Experimental Animals.

\section{Consent for publication}

Not applicable

\section{References}

1. Kalia LV, Lang AE. Parkinson's disease. LANCET 2015; 386 (9996):896-912.

2. Dopaminergic Loss and Inclusion Body Formation in $\sqcup$-Synuclein Mice: Implications for Neurodegenerative Disorders.

3. Sahli H, Seddik L, Remy P. [Non-motor symptoms of Parkinson disease and their management]. Rev Prat 2018; 68 (5):508-512.

4. Ascherio A, Schwarzschild MA. The epidemiology of Parkinson's disease: risk factors and prevention. LANCET NEUROL 2016; 15 (12):1257-1272.

5. Bryois J, Skene NG, Hansen TF et al.. Genetic identification of cell types underlying brain complex traits yields insights into the etiology of Parkinson's disease. NAT GENET 2020.

6. White DL, Kunik ME, Yu H et al.. Post-Traumatic Stress Disorder is Associated with further Increased Parkinson's Disease Risk in Veterans with Traumatic Brain Injury. ANN NEUROL 2020.

7. Ascherio A, Schwarzschild MA. The epidemiology of Parkinson's disease: risk factors and prevention. LANCET NEUROL 2016; 15 (12):1257-1272.

8. Langston JW. The promise of stem cells in Parkinson disease. J CLIN INVEST 2005; 115 (1):23-25.

9. Iacono RP, Henderson JM, Lonser RR. Combined stereotactic thalamotomy and posteroventral pallidotomy for Parkinson's disease. J Image Guid Surg 1995; 1 (3):133-140. 
10. Raza C, Anjum R, Shakeel NUA. Parkinson's disease: Mechanisms, translational models and management strategies. LIFE SCI 2019; 226:77-90.

11. Barker RA. Designing stem-cell-based dopamine cell replacement trials for Parkinson's disease. NAT MED 2019; 25 (7):1045-1053.

12. Svendsen CN, Langston JW. Stem cells for Parkinson disease and ALS: replacement or protection? NAT MED 2004; 10 (3 ):224-225.

13. Barker RA, Drouin-Ouellet J, Parmar M et al.. Cell-based therapies for Parkinson disease-past insights and future potential. Nature reviews. Neurology 2015; 11 (9):492-503.

14. Barker RA, de Beaufort I. Scientific and ethical issues related to stem cell research and interventions in neurodegenerative disorders of the brain. PROG NEUROBIOL 2013; 110:63-73.

15. Takahashi K, Okita K, Nakagawa M, Yamanaka S. Induction of pluripotent stem cells from fibroblast cultures. NAT PROTOC 2007; 2 (12):3081-3089.

16. Amin N, Tan X, Ren Q et al.. Recent advances of induced pluripotent stem cells application in neurodegenerative diseases. Prog Neuropsychopharmacol Biol Psychiatry 2019; 95:109674.

17. Henry MP, Hawkins JR, Boyle J, Bridger JM. The Genomic Health of Human Pluripotent Stem Cells: Genomic Instability and the Consequences on Nuclear Organization. FRONT GENET 2018; 9:623.

18. Pittenger MF, Mackay AM, Beck SC et al.. Multilineage potential of adult human mesenchymal stem cells. SCIENCE 1999; 284 (5411):143-147.

19. Hayashi T, Wakao S, Kitada M et al.. Autologous mesenchymal stem cell-derived dopaminergic neurons function in parkinsonian macaques. J CLIN INVEST 2013; 123 (1):272-284.

20. Uccelli A, Moretta L, Pistoia V. Mesenchymal stem cells in health and disease. NAT REV IMMUNOL 2008; 8 (9):726-736.

21. Bernardo ME, Fibbe WE. Mesenchymal stromal cells: sensors and switchers of inflammation. CELL STEM CELL 2013; 13 (4):392-402.

22. Sun Y, Selvaraj S, Pandey S et al.. MPP(+) decreases store-operated calcium entry and TRPC1 expression in Mesenchymal Stem Cell derived dopaminergic neurons. Sci Rep 2018; 8 (1):11715.

23. Singh M, Kakkar A, Sharma R et al.. Synergistic Effect of BDNF and FGF2 in Efficient Generation of Functional Dopaminergic Neurons from human Mesenchymal Stem Cells. Sci Rep 2017; 7 (1):10378.

24. Black IB, Woodbury D. Adult Rat and Human Bone Marrow Stromal Stem Cells Differentiate into Neurons. Blood Cells, Molecules, and Diseases 2001; 27 (3):632-636.

25. Barzilay R, Ben-Zur T, Bulvik S, Melamed E, Offen D. Lentiviral Delivery ofLMX1a Enhances Dopaminergic Phenotype in Differentiated Human Bone Marrow Mesenchymal Stem Cells. STEM CELLS DEV 2009; 18 (4):591-602.

26. Trzaska KA, King CC, Li KY et al.. Brain-derived neurotrophic factor facilitates maturation of mesenchymal stem cell-derived dopamine progenitors to functional neurons. J NEUROCHEM 2009; 110 (3):1058-1069. 
27. Trzaska KA, Kuzhikandathil EV, Rameshwar P. Specification of a dopaminergic phenotype from adult human mesenchymal stem cells. STEM CELLS 2007; 25 (11):2797-2808.

28. Jakobsson T, Treuter E, Gustafsson JA, Steffensen KR. Liver X receptor biology and pharmacology: new pathways, challenges and opportunities. TRENDS PHARMACOL SCI 2012; 33 (7):394-404.

29. Hong C, Tontonoz P. Liver $X$ receptors in lipid metabolism: opportunities for drug discovery. NAT REV DRUG DISCOV 2014; 13 (6):433-444.

30. Gavini CK, Bookout AL, Bonomo R et al.. Liver X Receptors Protect Dorsal Root Ganglia from ObesityInduced Endoplasmic Reticulum Stress and Mechanical Allodynia. CELL REP 2018; 25 (2):271-277.

31. Theofilopoulos S, Arenas E. Liver X receptors and cholesterol metabolism: role in ventral midbrain development and neurodegeneration. F1000Prime Reports 2015; 7:37.

32. Cai $Y$, Tang $X$, Chen $X$ et al.. Liver $X$ receptor beta regulates the development of the dentate gyrus and autistic-like behavior in the mouse. Proc Natl Acad Sci U S A 2018; 115 (12):E2725-E2733.

33. Dai $Y$, Wu W, Huang $B$ et al.. Liver $X$ receptors regulate cerebrospinal fluid production. MOL PSYCHIATR 2016; 21 (6):844-856.

34. Meffre D, Shackleford G, Hichor $M$ et al.. Liver $X$ receptors alpha and beta promote myelination and remyelination in the cerebellum. Proc Natl Acad Sci U S A 2015; 112 (24):7587-7592.

35. Theofilopoulos S, Griffiths WJ, Crick PJ et al.. Cholestenoic acids regulate motor neuron survival via liver X receptors. J CLIN INVEST 2014; 124 (11):4829-4842.

36. Koldamova RP, Lefterov IM, Staufenbiel M et al.. The liver X receptor ligand T0901317 decreases amyloid beta production in vitro and in a mouse model of Alzheimer's disease. J BIOL CHEM 2005; 280 (6):4079-4088.

37. Riddell DR, Zhou H, Comery TA et al.. The LXR agonist T0901317 selectively lowers hippocampal Abeta42 and improves memory in the Tg2576 mouse model of Alzheimer's disease. MOL CELL NEUROSCI 2007; 34 (4):621-628.

38. Paterniti I, Campolo M, Siracusa R et al.. Liver X receptors activation, through T0901317 binding, reduces neuroinflammation in Parkinson's disease. PLOS ONE 2017; 12 (4):e174470.

39. Cheng 0 , Tian $X$, Luo $Y$ et al.. Liver $X$ receptors agonist promotes differentiation of rat bone marrow derived mesenchymal stem cells into dopaminergic neuron-like cells. Oncotarget 2018; 9 (1):576-590.

40. Kirkeby A, Nolbrant S, Tiklova $\mathrm{K}$ et al.. Predictive Markers Guide Differentiation to Improve Graft Outcome in Clinical Translation of hESC-Based Therapy for Parkinson's Disease. CELL STEM CELL 2017; 20 (1):135-148.

41. Kirik D, Rosenblad C, Bjorklund A. Characterization of behavioral and neurodegenerative changes following partial lesions of the nigrostriatal dopamine system induced by intrastriatal 6hydroxydopamine in the rat. EXP NEUROL 1998; 152 (2):259-277.

42. Tropepe V, Hitoshi S, Sirard C et al.. Direct neural fate specification from embryonic stem cells: a primitive mammalian neural stem cell stage acquired through a default mechanism. NEURON 2001; 30 (1):65. 
43. Wislet-Gendebien S, Leprince P, Moonen G, Rogister B. Regulation of neural markers nestin and GFAP expression by cultivated bone marrow stromal cells. J CELL SCI 2003; 116 (Pt 16):3295-3302.

44. Tondreau T, Lagneaux $L$, Dejeneffe $M$ et al.. Bone marrow-derived mesenchymal stem cells already express specific neural proteins before any differentiation. DIFFERENTIATION 2004; 72 (7):319-326.

45. Blondheim NR, Levy YS, Ben-Zur T et al.. Human mesenchymal stem cells express neural genes, suggesting a neural predisposition. STEM CELLS DEV 2006; 15 (2):141-164.

46. Deng J, Petersen BE, Steindler DA, Jorgensen ML, Laywell ED. Mesenchymal stem cells spontaneously express neural proteins in culture and are neurogenic after transplantation. STEM CELLS 2006; 24 (4):1054-1064.

47. Evangelista AF, Vannier-Santos MA, de Assis SG et al.. Bone marrow-derived mesenchymal stem/stromal cells reverse the sensorial diabetic neuropathy via modulation of spinal neuroinflammatory cascades. J Neuroinflammation 2018; 15 (1):189.

48. Whone AL, Kemp K, Sun M, Wilkins A, Scolding NJ. Human bone marrow mesenchymal stem cells protect catecholaminergic and serotonergic neuronal perikarya and transporter function from oxidative stress by the secretion of glial-derived neurotrophic factor. BRAIN RES 2012; 1431:86-96.

49. Scheper V, Schwieger J, Hamm A, Lenarz T, Hoffmann A. BDNF-overexpressing human mesenchymal stem cells mediate increased neuronal protection in vitro. J NEUROSCI RES 2019; 97 (11):1414-1429.

50. Xiong N, Yang H, Liu L et al.. bFGF promotes the differentiation and effectiveness of human bone marrow mesenchymal stem cells in a rotenone model for Parkinson's disease. Environ Toxicol Pharmacol 2013; 36 (2):411-422.

51. Forget C, Stewart J, Trudeau L. Impact of basic FGF expression in astrocytes on dopamine neuron synaptic function and development. EUR J NEUROSCI 2006; 23 (3):608-616.

52. Yang F, Liu Y, Tu J et al.. Activated astrocytes enhance the dopaminergic differentiation of stem cells and promote brain repair through bFGF. NAT COMMUN 2014; 5 (1).

53. O'Malley EK, Sieber BA, Morrison RS, Black IB, Dreyfus CF. Nigral type I astrocytes release a soluble factor that increases dopaminergic neuron survival through mechanisms distinct from basic fibroblast growth factor. BRAIN RES 1994; 647 (1):83.

54. Chadi G, Moller A, Rosen L et al.. Protective actions of human recombinant basic fibroblast growth factor on MPTP-lesioned nigrostriatal dopamine neurons after intraventricular infusion. EXP BRAIN RES 1993; 97 (1):145-158.

55. Fuccillo M, Joyner AL, Fishell G. Morphogen to mitogen: the multiple roles of hedgehog signalling in vertebrate neural development. NAT REV NEUROSCI 2006; 7 (10):772-783.

56. Ruiz IAA, Palma V, Dahmane N. Hedgehog-Gli signalling and the growth of the brain. NAT REV NEUROSCI 2002; 3 (1):24-33.

57. Traiffort $E$, Angot E, Ruat M. Sonic Hedgehog signaling in the mammalian brain. J NEUROCHEM 2010; 113 (3):576-590. 
58. Ahn S, Joyner AL. In vivo analysis of quiescent adult neural stem cells responding to Sonic hedgehog. NATURE 2005; 437 (7060):894-897.

59. Hill SA, Blaeser AS, Coley AA et al.. Sonic hedgehog signaling in astrocytes mediates cell typespecific synaptic organization. ELIFE 2019; 8.

60. Miller AV, Kavanaugh SI, Tsai PS. Disruption of the Suprachiasmatic Nucleus in Fibroblast Growth Factor Signaling-Deficient Mice. Front Endocrinol (Lausanne) 2016; 7:11.

61. McCabe MJ, Gaston-Massuet C, Tziaferi V et al.. Novel FGF8 mutations associated with recessive holoprosencephaly, craniofacial defects, and hypothalamo-pituitary dysfunction. J Clin Endocrinol Metab 2011; 96 (10):E1709-E1718.

62. Ye W, Shimamura K, Rubenstein JL, Hynes MA, Rosenthal A. FGF and Shh signals control dopaminergic and serotonergic cell fate in the anterior neural plate. CELL 1998; 93 (5):755-766.

63. Roussa E, Farkas LM, Krieglstein K. TGF-beta promotes survival on mesencephalic dopaminergic neurons in cooperation with Shh and FGF-8. NEUROBIOL DIS 2004; 16 (2):300-310.

64. Fitz NF, Carter AY, Tapias V et al.. ABCA1 Deficiency Affects Basal Cognitive Deficits and Dendritic Density in Mice. J ALZHEIMERS DIS 2017; 56 (3):1075-1085.

65. Cui X, Chopp M, Zhang Z et al.. ABCA1/ApoE/HDL Pathway Mediates GW3965-Induced Neurorestoration After Stroke. STROKE 2017; 48 (2):459-467.

66. Lee HJ, Ryu JM, Jung YH et al.. High glucose upregulates BACE1-mediated A $\beta$ production through ROS-dependent HIF-1a and LXRa/ABCA1-regulated lipid raft reorganization in SK-N-MC cells. SCI REP-UK 2016; 6 (1).

67. Trzaska KA, Kuzhikandathil EV, Rameshwar P. Specification of a dopaminergic phenotype from adult human mesenchymal stem cells. STEM CELLS 2007; 25 (11):2797-2808.

68. Trzaska KA, Reddy BY, Munoz JL et al.. Loss of RE-1 silencing factor in mesenchymal stem cellderived dopamine progenitors induces functional maturity. MOL CELL NEUROSCI 2008; 39 (2):285290.

69. Mu T, Qin Y, Liu B et al.. In Vitro Neural Differentiation of Bone Marrow Mesenchymal Stem Cells Carrying the FTH1 Reporter Gene and Detection with MRI. BIOMED RES INT 2018; 2018:1978602.

70. Cheng 0 , Tian $X$, Luo $Y$ et al.. Liver $X$ receptors agonist promotes differentiation of rat bone marrow derived mesenchymal stem cells into dopaminergic neuron-like cells. Oncotarget 2018; 9 (1):576-590.

71. Mohammad MH, Al-Shammari AM, Al-Juboory AA, Yaseen NY. Characterization of neural stemness status through the neurogenesis process for bone marrow mesenchymal stem cells. Stem Cells Cloning 2016; 9:1-15.

72. Karasinska JM, Rinninger F, Lutjohann D et al.. Specific Loss of Brain ABCA1 Increases Brain Cholesterol Uptake and Influences Neuronal Structure and Function. J NEUROSCI 2009; 29 (11):35793589 .

73. Wang Y, Chen X, Armstrong MA, Li G. Survival of bone marrow-derived mesenchymal stem cells in a xenotransplantation model. J ORTHOP RES 2007; 25 (7):926-932. 
74. Nakamura $Y$, Wang $X, X u C$ et al.. Xenotransplantation of long-term-cultured swine bone marrowderived mesenchymal stem cells. STEM CELLS 2007; 25 (3):612-620.

75. Le Blanc K, Tammik C, Rosendahl K, Zetterberg E, Ringden O. HLA expression and immunologic properties of differentiated and undifferentiated mesenchymal stem cells. EXP HEMATOL 2003; 31 (10):890-896.

76. Tse WT, Pendleton JD, Beyer WM, Egalka MC, Guinan EC. Suppression of allogeneic T-cell proliferation by human marrow stromal cells: implications in transplantation. TRANSPLANTATION 2003; 75 (3):389-397.

\section{Figures}
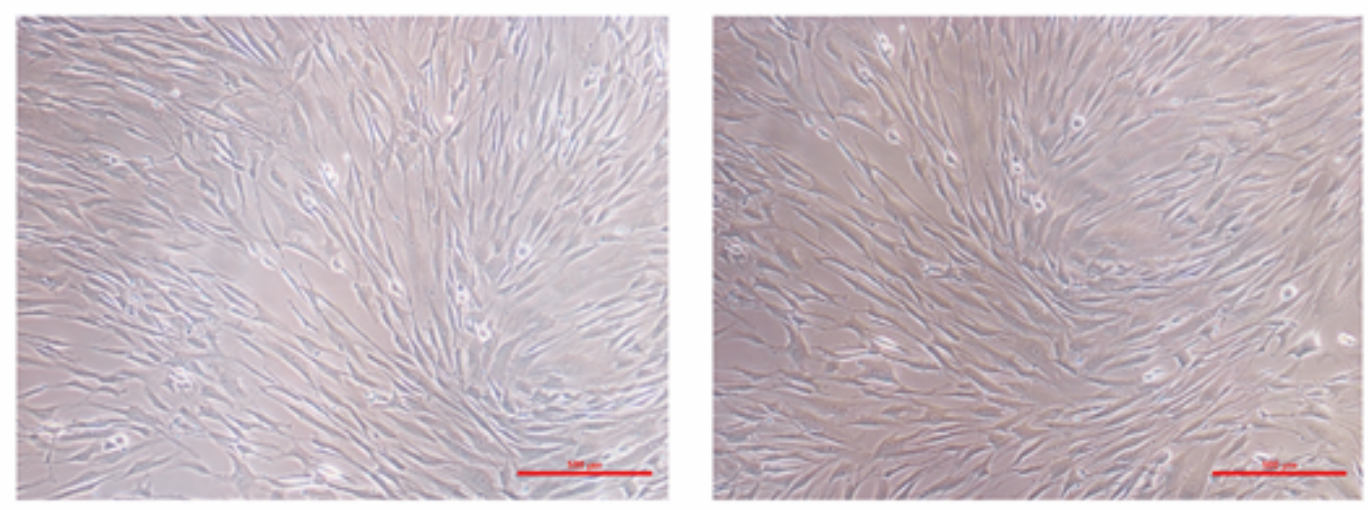

Figure 1

hBMSCs were observed at inverted microscope and showed a fibroblastoid cell profile and produced cell colonies with unique vortex shape. 
A

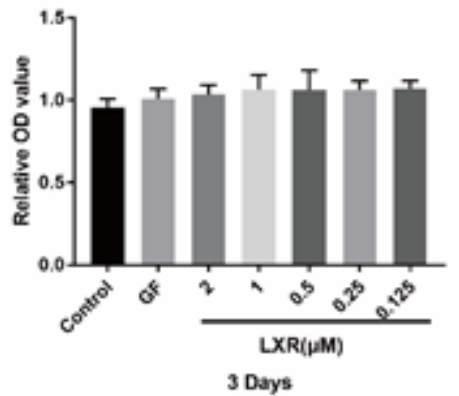

C

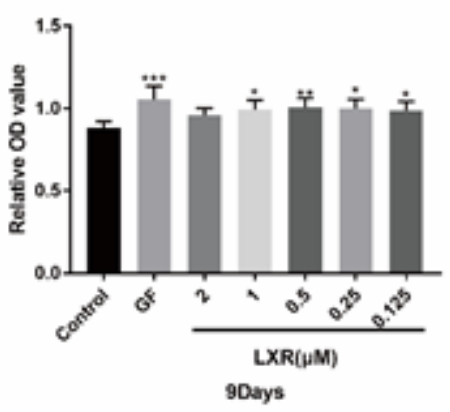

B

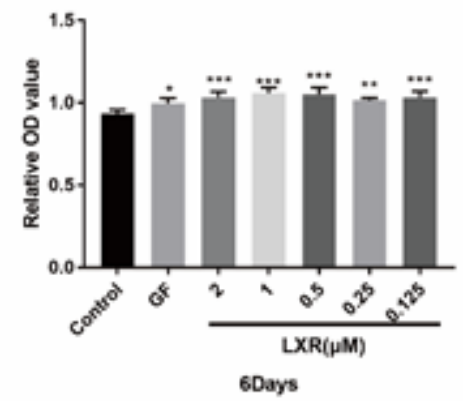

D

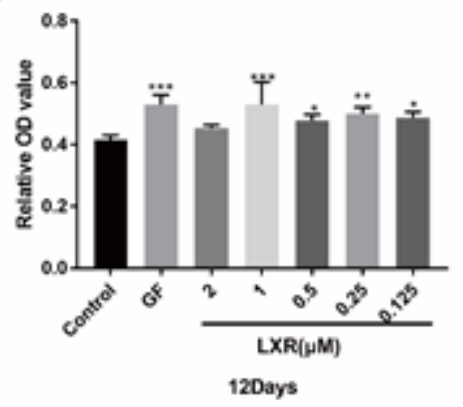

\section{Figure 2}

Different concentrations of T0901317 were supplemented into the medium to examine the effect of T0901317 on the viability of hBMSCs. (A) Culture for 3 days. (B) Culture for 6 days. (C) Culture for 9 days. (D) Culture for 12 days. Data were expressed as mean $\pm S D(n=6)$. ${ }^{\star} P<0.05,{ }^{\star *} P<0.01$, ${ }^{\star \star *} P<$ 0.001 , compared with control group. 


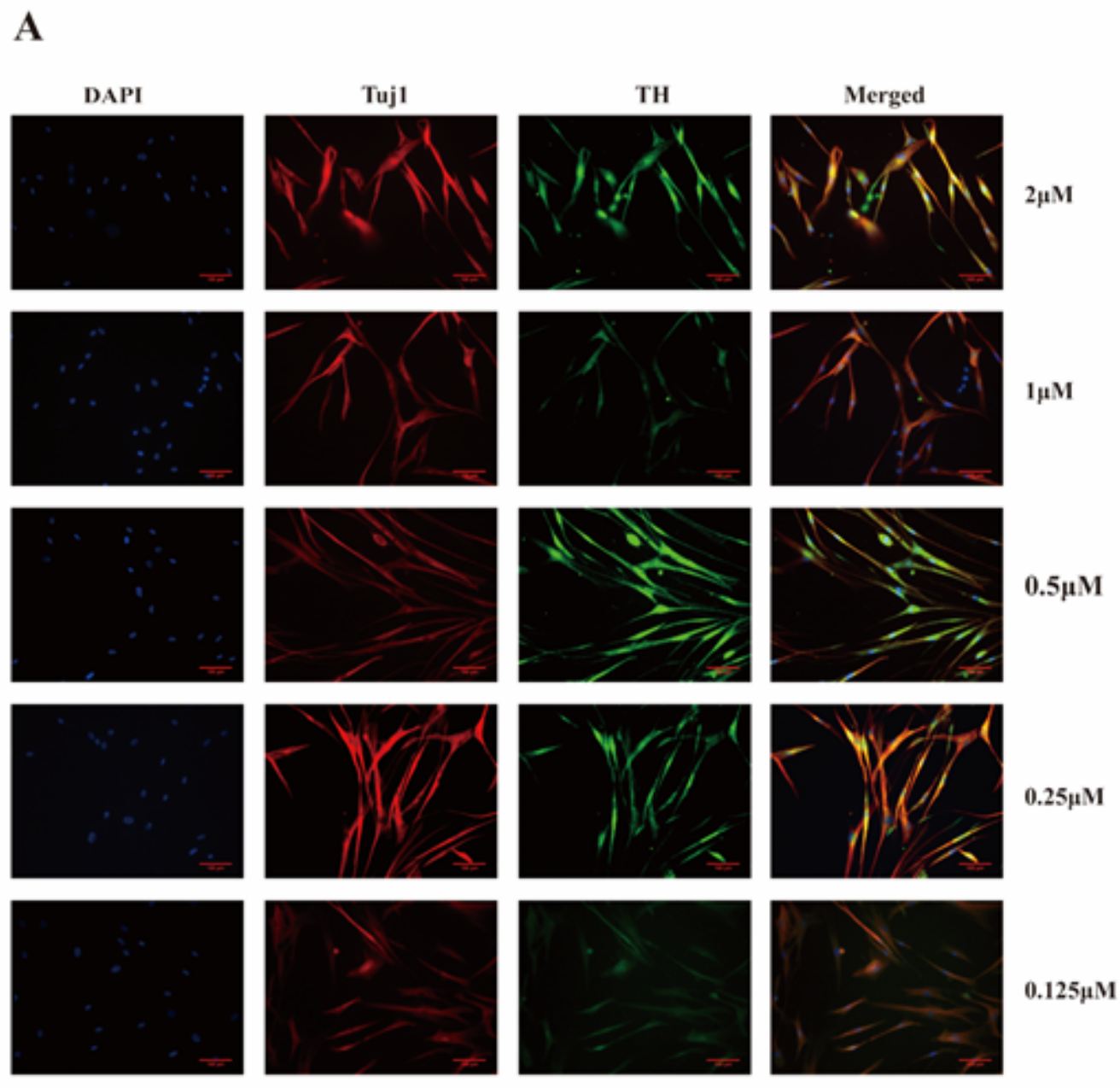

B

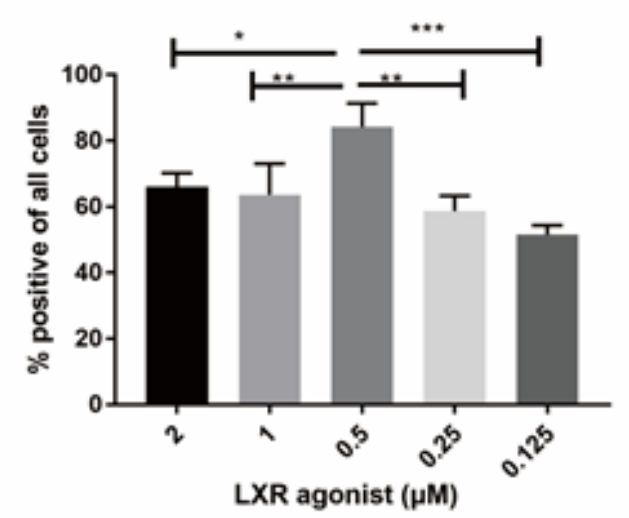

Figure 3

The optimal concentration of T0901317. $(200 \times$, Scale bars $=100 \mu \mathrm{m})$. (A) The rate of TH+ positive cells reached the maximum under the induction of $0.5 \square \mathrm{M}$ T0901317. (B) Group data showed change in expression of TH. Data were expressed as mean $\pm S D(n=6)$. ${ }^{*} P<0.05,{ }^{* * P}<0.01$, ${ }^{\star \star *} P<0.001$, compared with concentration of $0.5 \mu \mathrm{M}$ T0901317. 
A
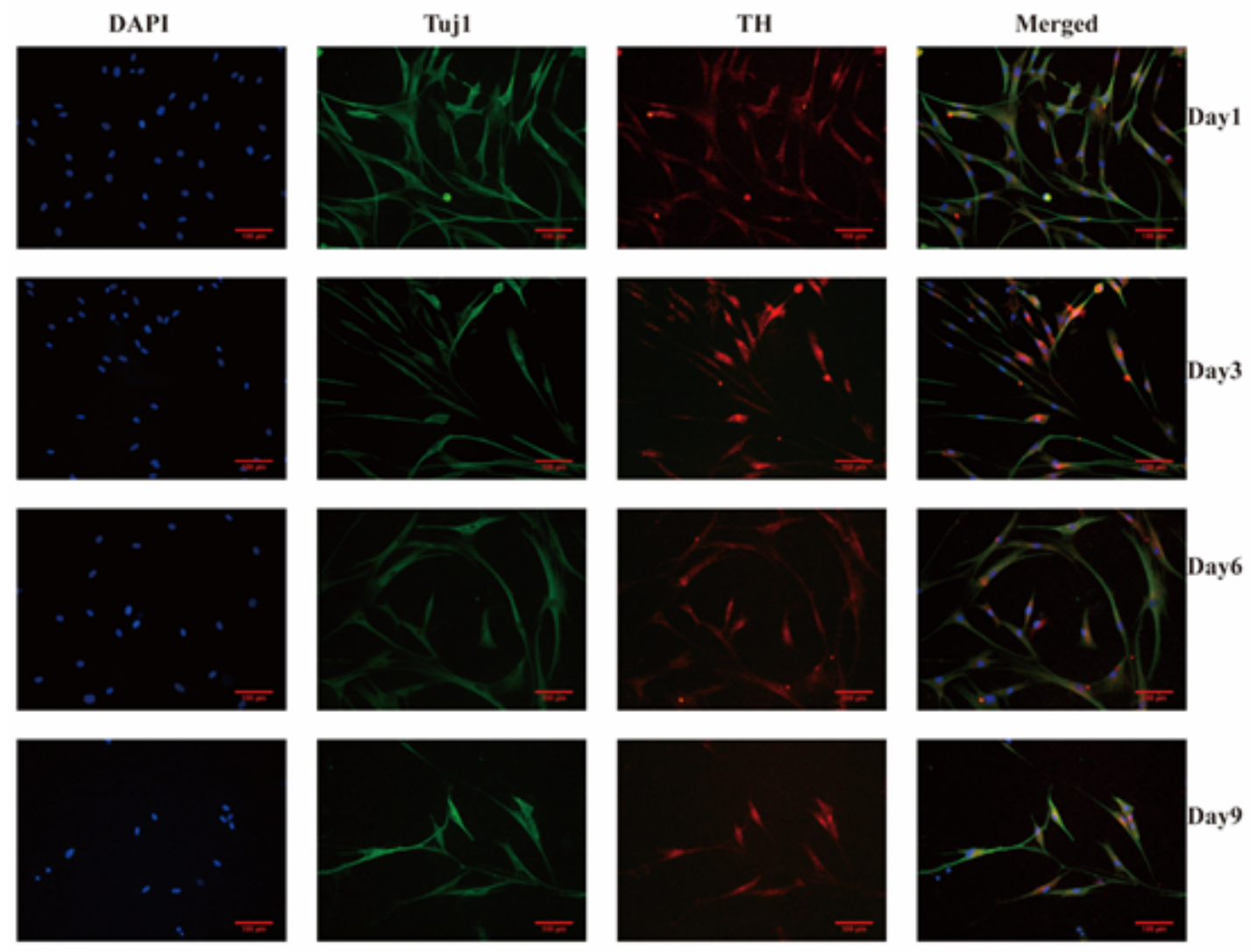

B

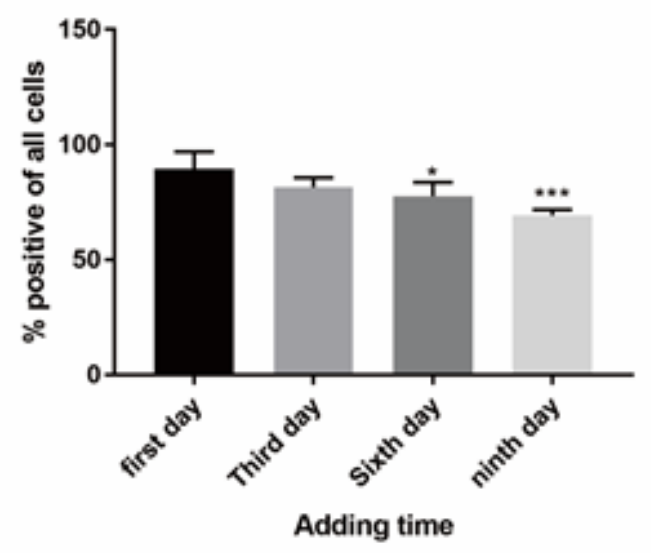

\section{Figure 4}

Exploring the best time to add T0901317 into GF (200x, Scale bars $=100 \square \mathrm{m})$. (A) The expressions of Tuj1 and TH between each group. (B) The statistic of TH+ cells between groups. Data were expressed as mean $\pm S D(n=6) . * P<0.5, * * * P<0.001$, compared with the first day group. 
A
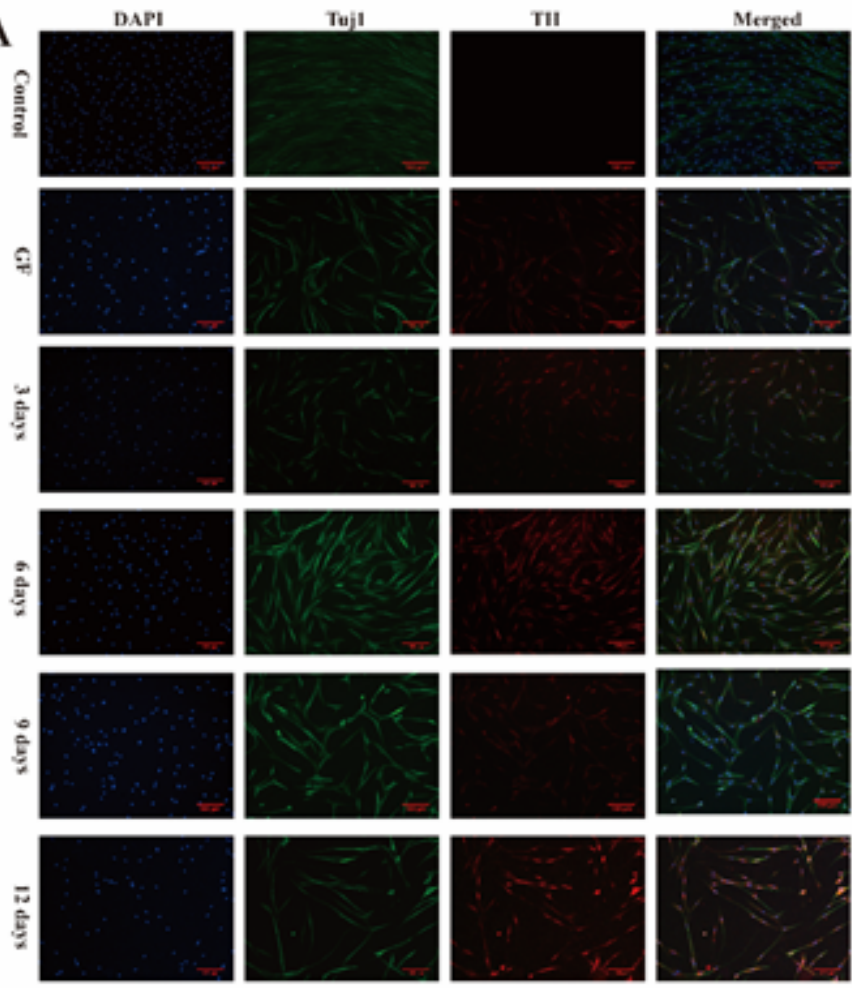

B

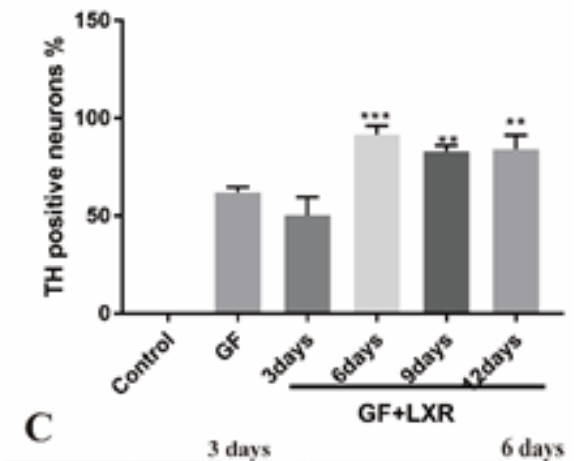

D

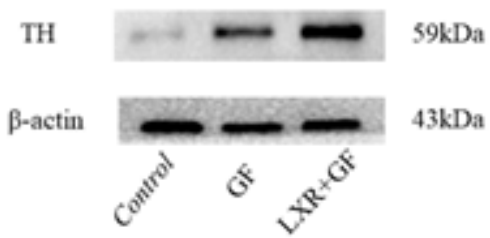

E

Control

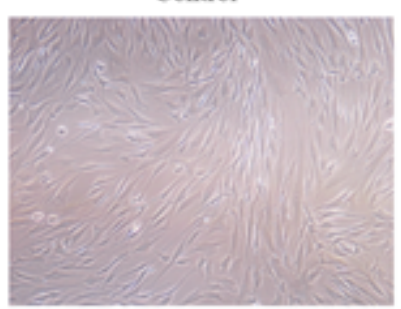

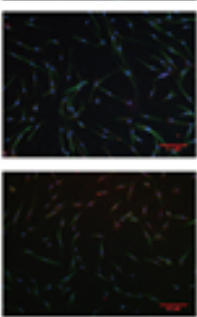
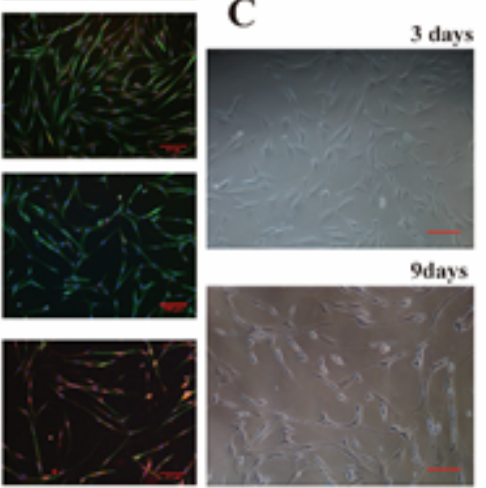

9days
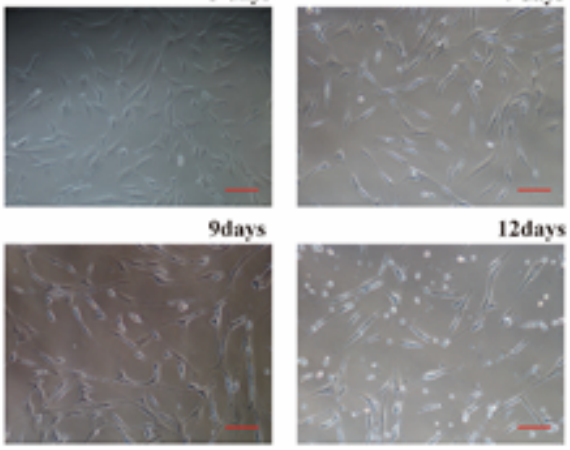

12 davs
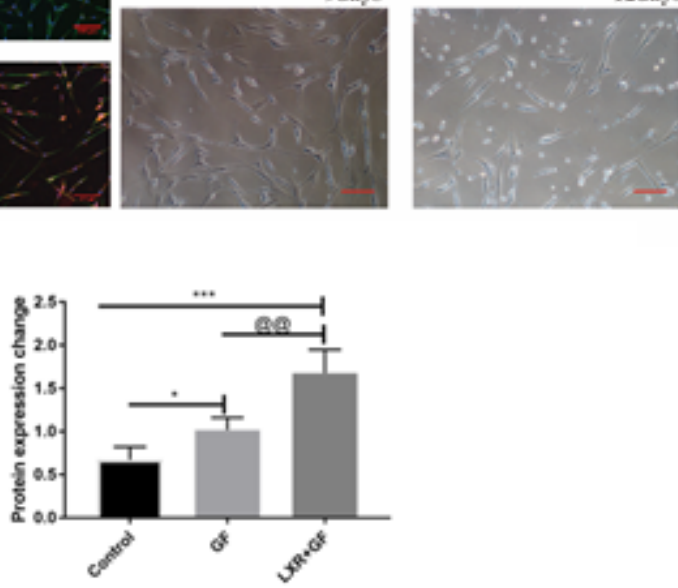

Tyrosine hydroxylase

GF

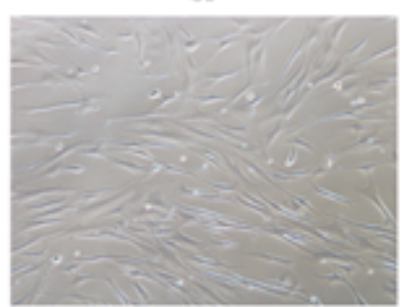

$\mathrm{LXR}+\mathrm{GF}$

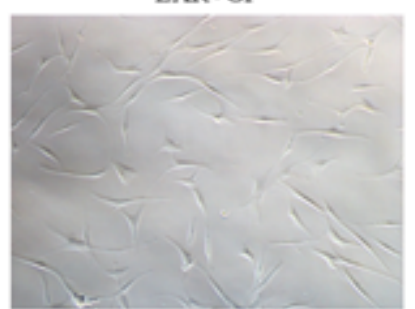

\section{Figure 5}

Explore the optimal period induced by T0901317. (A) The expressions of Tuj1 (Alexa Fluor 488, green) and TH (Cy3, red) were showed in each group (200x). (B) Counting TH+ cells between groups. Data were

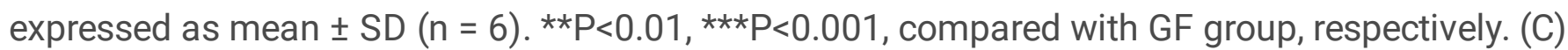
Morphological changes of cells under different induction periods (100x). (D) Expression changes of tyrosine hydroxylase was detected by Western blotting. Data were expressed as mean $\pm S D(n=3)$. ${ }^{\star} \mathrm{P}<0.05$, ${ }^{\star \star *} \mathrm{P}<0.001$, compared with control group, respectively. @@P $<0.01$, compared with GF group. (E) Bright-field images of hBMSCs in different groups by cultivating for six days (100x). 
A
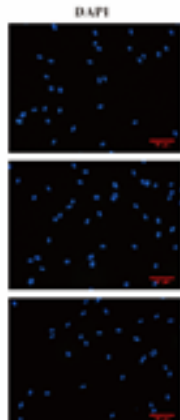

B
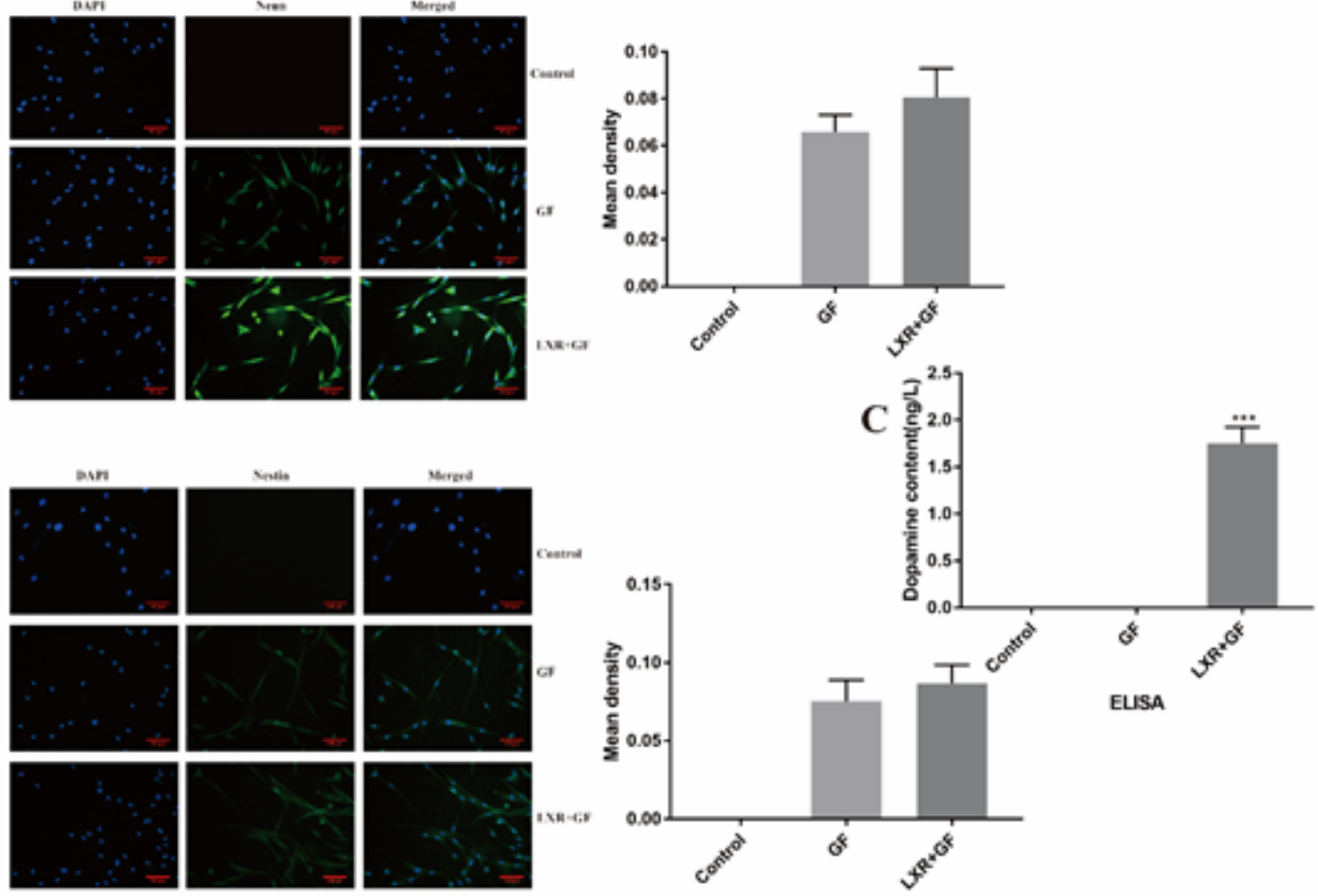

\section{Figure 6}

Nestin, Neun expression and dopamine release. (200x, Scale bars $=100 \square \mathrm{m})$. (A) The expression of neun. Data were expressed as mean $\pm S D(n=3)$. (B) The expression of nestin. Data were expressed as mean \pm $S D(n=3)$. (C) Secretion of dopamine. Data were expressed as mean $\pm S D(n=3) . * \star * P<0.001$, comparison of the expression of dopamine by LXR+GF group. 

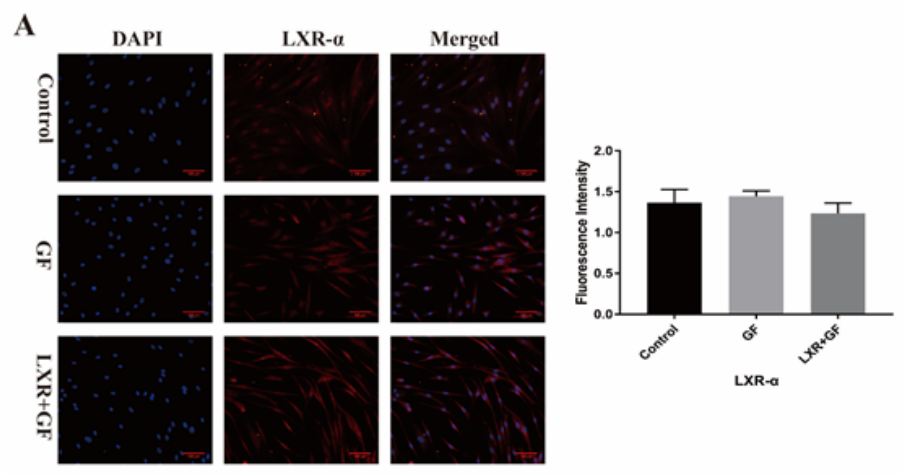

C
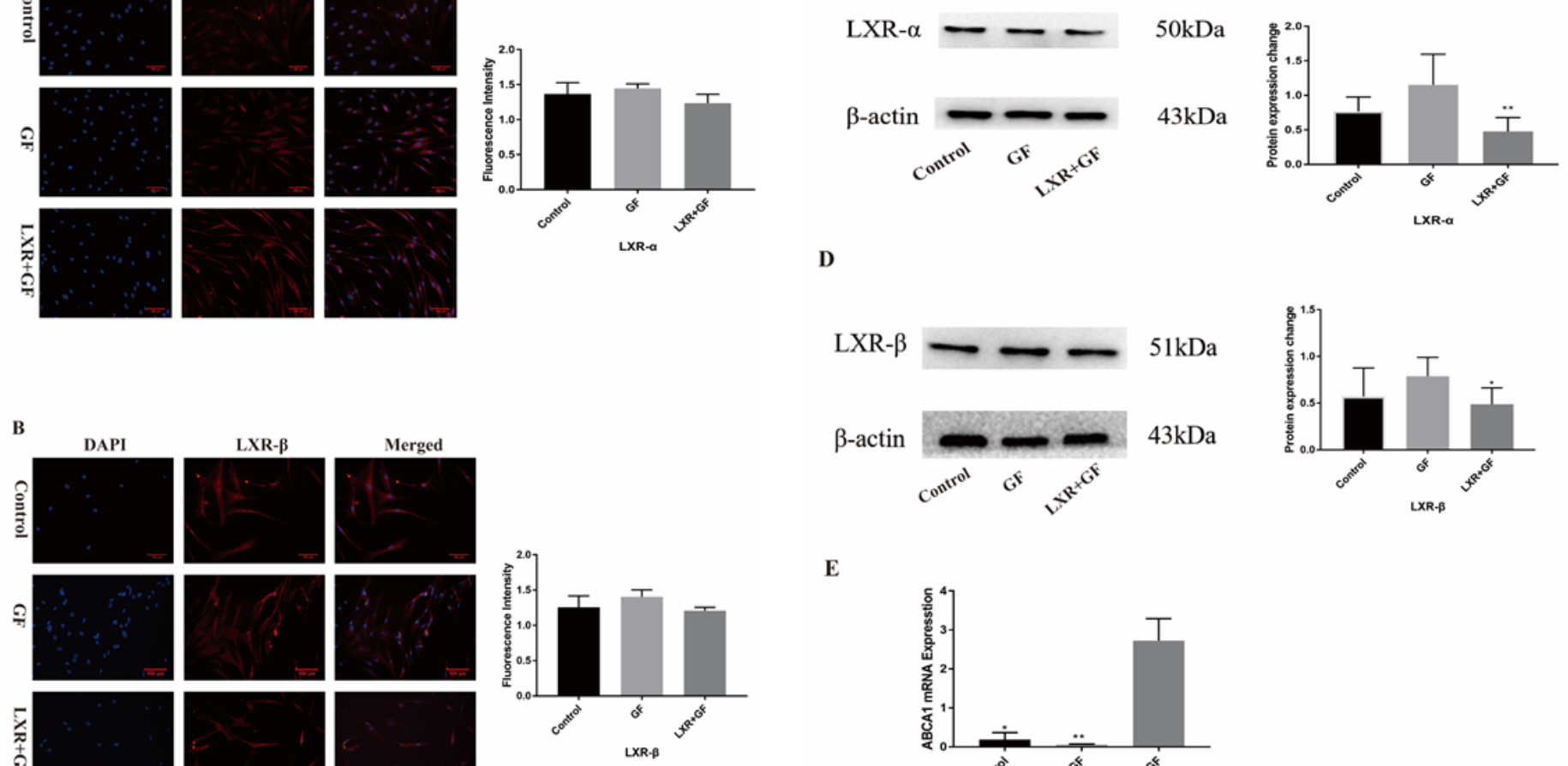

D
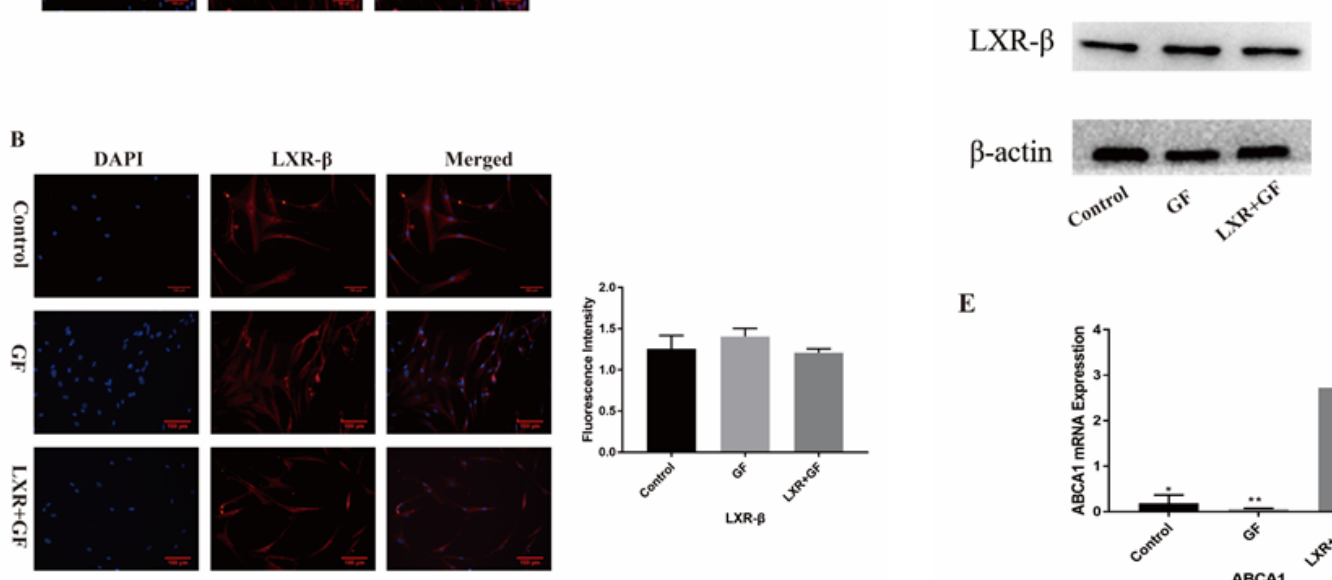

$51 \mathrm{kDa}$

$43 \mathrm{kDa}$

E
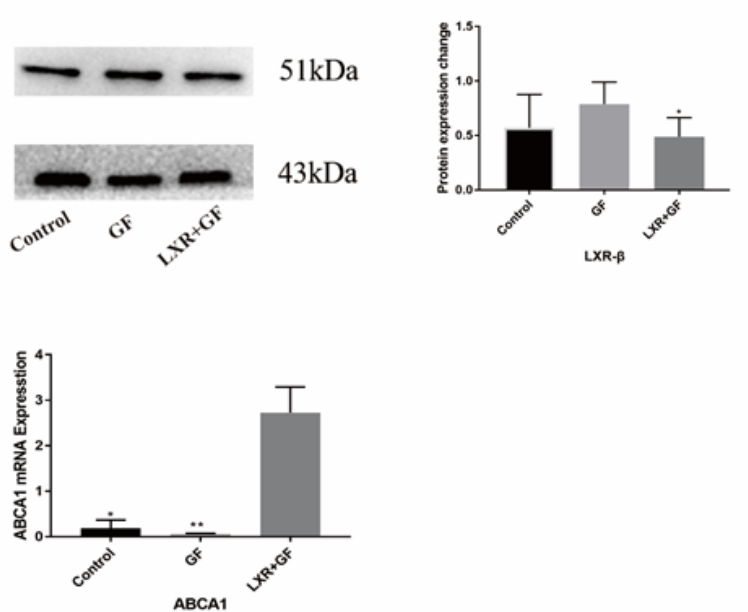

Figure 7

Changes in expressions of LXRs (200x, Scale bars $=100 \mu \mathrm{m})$. (A, B) Expressions of LXRa and LXR $\beta$ $(n=3)$. $(C, D)$ The expression of LXRs protein. Data were expressed as mean $\pm S D(n=3) .{ }^{*}<0.05$, $\star * P<0.01$, compared with GF group. (E) Changes in expression of ABCA1mRNA. Data were expressed as mean $\pm S D(n=3)$. ${ }^{*}<<0.05,{ }^{*} P<0.01$, compared with LXR+GF group.

A

TH

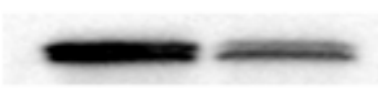

$\beta$-actin

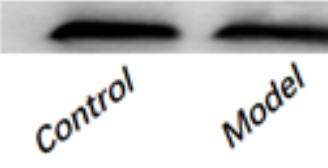

C

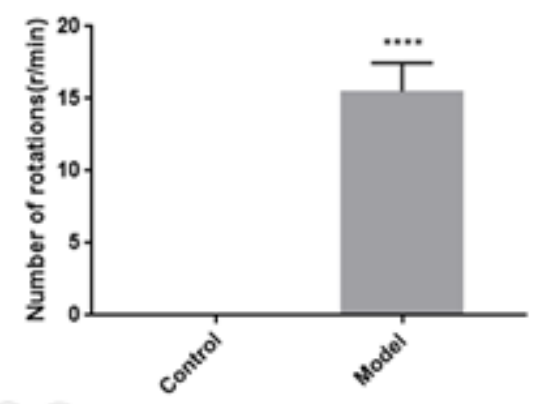

B

$59 K D$

43KD

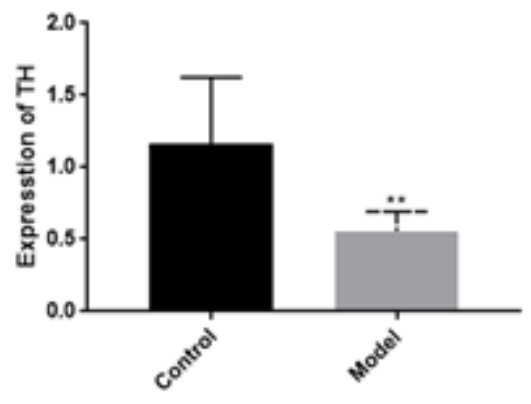




\section{Figure 8}

Establishment of SD rat Parkinson model. (A) The expression of TH protein in each group $(n=3)$. (B) Data were expressed as mean $\pm S D(n=3)$. ${ }^{\star} P<0.01$, compared with control group. (C) Rotational revolutions per minute. Data were expressed as mean $\pm S D(n=6) . * \star \star * P<0.0001$, compared with control group.

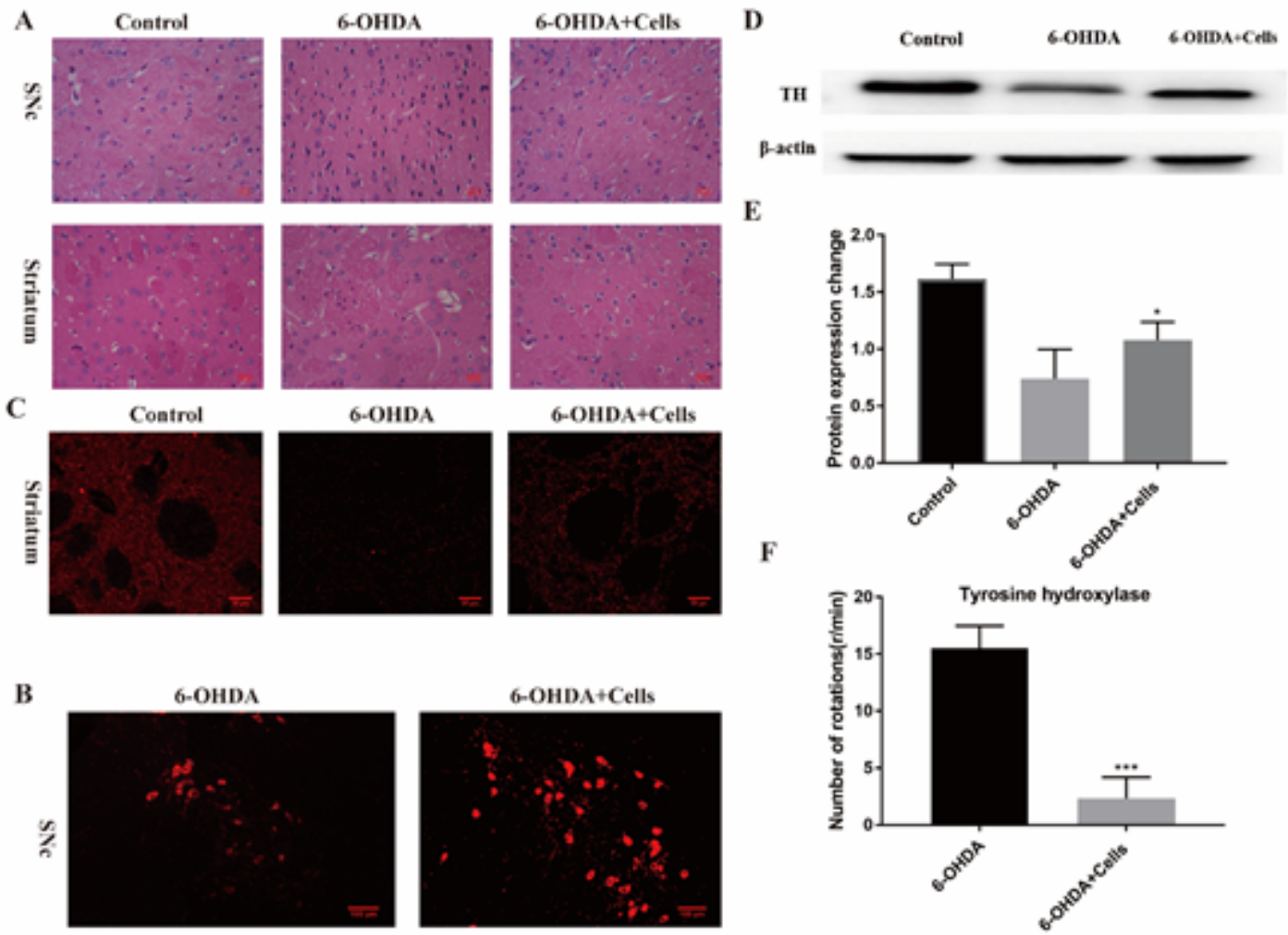

Figure 9

The results of cell transplantation. (A) The results of $\mathrm{HE}$ in each group. $(B, C) \mathrm{TH}$ immunofluorescent staining for $\mathrm{TH}$ in SNc and striatum of each group. $(\mathrm{D}, \mathrm{E})$ The expression of $\mathrm{TH}$. Data were expressed as mean $\pm S D(n=3) . * P<0.05$, compared with 6-OHDA group. $(F)$ The results of apomorphine-induced rotations from each group. Data were expressed as mean $\pm S D(n=6) .{ }^{\star * \star P} P<0.001$, compared with 6OHDA group.

\section{Supplementary Files}

This is a list of supplementary files associated with this preprint. Click to download.

- SupplementaryMaterial.pdf 